\title{
Ultrastructure of the Fertilized Egg Envelope from Pseudobagrus fulvidraco, Bagridae, Teleostei
}

\author{
Joon Hyung Sohn, Ohyun Kwon ${ }^{1}$, Dong Heui Kim ${ }^{2, *}$ \\ Institute of Lifestyle Medicine, Yonsei University Wonju College of Medicine, Wonju 26426, Korea \\ ${ }^{1}$ Department of Visual Optics, Division of Health Science, Baekseok University, Cheonan 31065, Korea \\ ${ }^{2}$ Department of Environmental Medical Biology, Yonsei University Wonju College of Medicine, Wonju 26426, Korea
}

*Correspondence to:

Kim DH,

Tel: $+82-33-741-0332$

Fax: $+82-33-731-6953$

E-mail: fish7963@yonsei.ac.kr

Received September 6, 2016

Revised September 20, 2016

Accepted September 21, 2016
The ultrastructure of fertilized egg envelope from Pseudobagrus fulvidraco belongs to Bagridae was investigated using light and electron microscopes. The fertilized egg was compressed spherical, light-yellowish, demersal, and adhesive. The size of fertilized egg is about $1.85 \pm 0.13 \mathrm{~mm}$, perivitelline space is not well developed, and there were no appendicular structures on the outer surface of egg envelope and oil droplets in vitelline membrane under light microscope. The micropyle was located in the animal pole of fertilized egg. Adhesive reticular fiber was covered fertilized egg envelope. The thickness of egg envelope was about 3.7 4.2 $\mu \mathrm{m}$, and the egg envelope consisted of two layers: an outer, electron-dense adhesive fibers layer and an simple inner layer with pore. Therefore, the ultrastructure of cross section of the fertilized egg envelope showed species specificity, but studies on the other species belongs to Bagridae were need to get correct information about common traits in family.

Key Words: Fertilized egg, Egg envelope, Korean bullhead, Pseudobagrus fulvidraco, Ultrastructure

\section{INTRODUCTION}

Korean bullhead (Pseudobagrus fulvidraco) belongs to Bagridae, Siluriformes, Teleostei is mostly found in China, Taiwan, Eastern Siberia, and Southwest Korea. This species is nocturnal, and live on tiny crustaceans, fish egg, and aquatic insects. Also the spawning season is known to around May to July (Kim \& Park, 2002).

The egg envelope has been called in many names such as chorion (Brivio et al., 1991; Brummett \& Dumont, 1981; Cameron \& Hunter, 1984), egg membrane (Stehr \& Hawkes, 1979), external membrane (Bell et al., 1969), capsule (Anderson, 1974), eggshell (Grierson \& Neville, 1981; OppenBerntsen et al., 1990), zona radiata (Schmehl \& Graham, 1987), zona pellucida interna (Hamazaki et al., 1989), and egg envelope (Joo \& Kim, 2013; Kwon et al., 2015). But, egg envelope is known to be most suitable term in teleost.
In teleost, fertilized eggs are encircled by egg envelope. The egg envelope function to gas exchange, selective transport of materials from environment into the egg, protections of physical impact, harmful chemicals and pathogens such as bacteria, fungus, and protozoa, and inhibition of polyspermy (Cameron \& Hunter, 1984; Donovan \& Hart, 1986; Harvey et al., 1983; Laale, 1980; Ohta \& Nashirozawa, 1996). The ultrastructure of fertilized egg envelopes showed same or different morphology in the same family or same genus (Joo \& Kim, 2013; Kim et al., 1999; Kwon et al., 2015). Also, even if there are same species, the ultrastructure is known to differ according to geographical location (Brummett \& Dumont, 1981).

Studies on the P. fulvidraco has been conducted about annual reproductive cycle (Lim \& Han, 1997), ultrastructure of spermatozoa (Lee, 1998), genetic diversity and population structure (Huh et al., 2007), effect of water temperatures and

(a) This is an open-access article distributed under the terms of the Creative Commons Attribution Non-Commercial License (http://creativecommons.org/licenses/by-nc/4.0) which permits unrestricted noncommercial use, distribution, and reproduction in any medium, provided the original work is properly cited.

Copyrights @ 2016 by Korean Society of Microscopy 
photoperiods on gonadal development (Lim \& Han, 2012). But there is no ultrastructural study on the fertilized egg envelope. So, we investigated the fertilized egg morphology and ultrastructure of fertilized egg envelope using light and electron microscopes to determine whether fertilized egg and fertilized egg envelope show the species specificity or have special structure, and to get the systematic morphological data for classification of species. Because of the fertilized egg envelope take advantage of good point that its ultrastructure of outer surface, micropyle, and the thin section are not changed from fertilized egg until the stage of before hatching.

\section{MATERIALS AND METHODS}

\section{Animals}

The fishes, $P$. fulvidraco ( $\mathrm{n}=4$, total length: $15 \sim 18 \mathrm{~cm}$ ) used in this study were donated from Inland Aquaculture Association (Chuncheon, Korea) in June 2016. The tap water used for rearing was treated with activated carbon filter (Hydro Cure; Aqua Purification Systems Inc., USA) to remove chlorine, and its temperature and $\mathrm{pH}$ were maintained at $25^{\circ} \mathrm{C} \pm 1^{\circ} \mathrm{C}$ and $6.7 \pm 0.5$, respectively. Biological filtration was performed using a canister filter (New classic $2217^{\mathrm{TM}}$; Eheim Co., Ltd., Germany), and excrement settled to the bottom of the water tank was eliminated by exchanging one-quarter of the water each week. An artificial light was illuminated for $10 \mathrm{~h}$ per day to simulate a daytime environment.

\section{Collection of Fertilized Eggs}

Ovulation was induced from intraperitoneal injection of Daesung Aqua HCG $^{\circledR}$ (Daesung Microbiological Labs, Co., Ltd., Korea) with $6 \mathrm{IU} \mathrm{g}^{-1}$ body weight. Matured eggs were obtained using the fingers gently squeeze the sides of the fish at a point just anterior to the anal fins in two days after hCG injection, and semen was obtained from matured male in the same squeezing method. To get the fertilized eggs, semen and egg were mixed. And, tap water was added in semen and egg mixture. Fertilized eggs with perivetelline space formation were used in this experiment. Fertilized eggs were measured for size $(\mathrm{n}=30)$ under light microscope and used as samples for morphological analysis.

\section{Electron Microscopy}

For transmission electron microscope (TEM) observation, fertilized eggs were fixed in $2.5 \%$ glutaraldehyde in $0.1 \mathrm{M}$ phosphate buffer ( $\mathrm{pH} 7.4)$ for $2 \mathrm{~h}$ at $4^{\circ} \mathrm{C}$. After prefixation, the specimens were washed twice in the same buffer solution and then postfixed in $1 \%$ osmium tetroxide in $0.1 \mathrm{M}$ phosphate buffer ( $\mathrm{pH}$ 7.4) for $2 \mathrm{~h}$ at room temperature. Specimens were dehydrated in ethanol, cleared in propylene oxide, and embedded in an Epon mixture. Ultrathin sections of Epon-embedded fertilized egg envelope were taken with an ultramicrotome (Ultracut $\mathrm{E}^{\circledR}$; Reichert-Jung, Austria) at a thickness of about $60 \mathrm{~nm}$. Tissue sections were mounted onto copper grids, double stained with uranyl acetate followed by lead citrate, and observed with a TEM (JEM 1200EX-II; JEOL, Japan) at $80 \mathrm{kv}$. For scanning electron microscope (SEM) observation, prefixation, postfixation and dehydration were conducted by following the same procedure as that for TEM. The samples were replaced with isoamyl acetate and critical point dried. The samples were coated with gold using an ion sputter (JFC-1100; JEOL). Subsequently, the outer surface of the fertilized egg envelope and micropyle was observed with a table top SEM (TM-1000; Hitachi, Japan).

\section{RESULTS AND DISCUSSION}

\section{Morphology of Fertilized Eggs}

Fertilized egg of $P$. fulvidraco was compressed spherical, lightyellowish, demersal, and adhesive. The size of fertilized egg is about $1.85 \pm 0.13 \mathrm{~mm}(\mathrm{n}=30)$, perivitelline space was not well developed, and there were no appendicular structures on the outer surface of egg envelope and oil droplets in vitelline membrane under light microscope (Fig. 1). Fertilized eggs from $P$. fulvidraco vary in size according to researchers (Kim \& Park, 2002). The reason seems to be related to the total size of the adult female. The fertilized eggs of fishes belongs to Belontiidae are spherical, pelagic and adhesive (Kim et al., 1999). And the fertilized eggs of fishes belongs to Cichlidae are ellipsoidal, demersal, and adhesive (Deung et al., 1997). The external shapes of fertilized egg were seen as common trait in each family. And fertilized eggs of Cyprinidae and

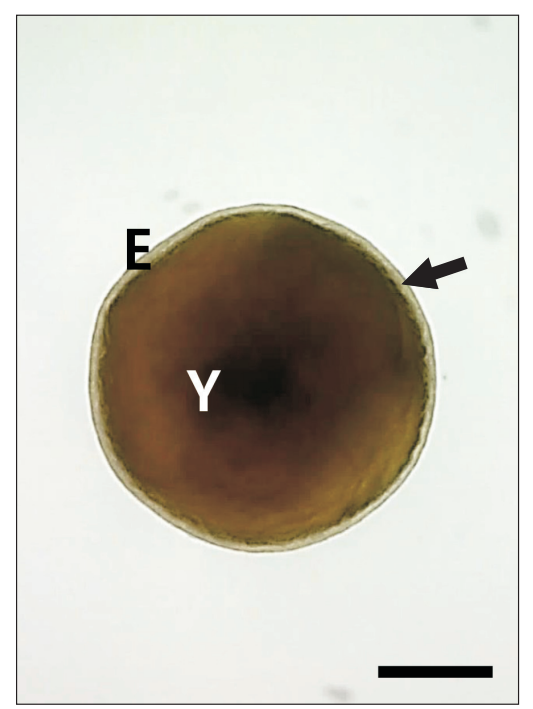

Fig. 1. Fertilized egg of Pseudobagrus fulvidraco was compressed spherical, light-yellowish, demersal, and adhesive. Perivitelline space was not well developed (scale bar=0.5 mm). E, egg envelope; Y, yolk. Arrow: perivitelline space. 
Characidae have similar morphology, but size of fertilized egg in two species differs from each other (Kim et al., 1996, 1998). In egg scatter such as Cyprinidae (Joo \& Kim, 2013; Kim et al., 1998) and Characidae (Kim et al., 1996), perivitelline space was well developed. But perivitelline space of species belongs to Cichlidae (Deung et al., 1997) and Nothobranchiidae (Kwon et al., 2015) along with P. fulvidraco is known to not develop because physical impact was not occurred during the spawning. Therefore, the size of perivitelline space seems to be related to spawning behavior. The morphology of fertilized egg showed similar pattern in family (Deung et al., 1997; Joo \& Kim, 2013; Kwon et al., 2015). The fertilized eggs of fishes belongs to Belontiidae have same morphology (Kim et al., 1999). We need morphological informations on the other species in Pseudobagrus to get the species specificity or family specificity.

\section{Outer Surfaces of the Fertilized Egg Envelopes}

In teleost, sperm have no acrosome in head part. So egg needs a sperm entry site on the egg envelope, micropyle on the egg envelope. Functions of micropyle are sperm passage and inhibition of poly spermy (Ohta \& Nashirozawa, 1996). Micropyle of some species show special external structures. The micropyle of Zacco platypus (Cyprinidae) is surrounded by 5 peaks of hill and those of Characidae are surrounded by spokes for bicycle like structure (Deung et al., 2000).

In our study, we found micropyle on the animal pole area of fertilized egg under SEM (Fig. 2 and 3). Micropyle was a funnel shape and non-spiral type unlike other species. Also, it looks like car wheel. Internal diameter of micropyle was $3 \mu \mathrm{m}$, external diameter was $12 \mu \mathrm{m}$ (Fig. 3).

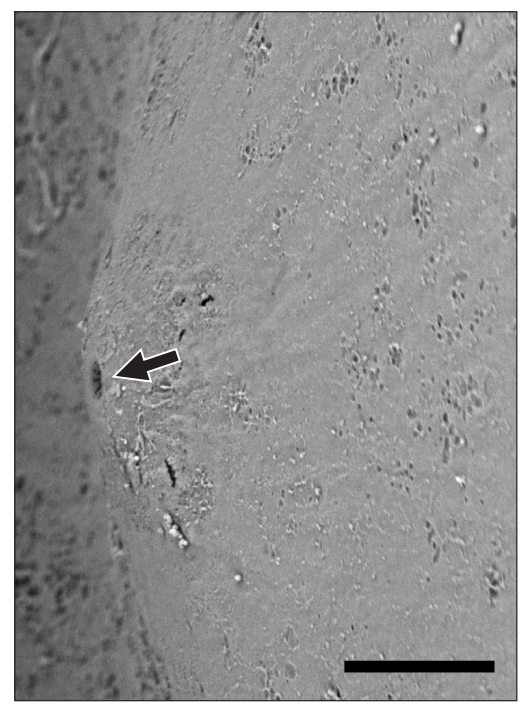

Fig. 2. Micropyle (arrow) was located on the animal pole of fertilized egg envelope. The outer surface was rough side in low magnification (scale bar=50 $\mu \mathrm{m})$.
Outer surface of fertilized egg envelope was a rough side in low magnification (Fig. 2). Adhesive reticular fiber was covered fertilized egg envelope, when magnified it. It looked like surface of basalt (Fig. 4). Fertilized eggs have special adhesive structure according to the species or family. In Cichlidae, fertilized egg envelopes were covered by reticular structure, and the fine structures were different according to the species (Kim et al., 1996, 1998). The non-adhesive fertilized egg of Danio rerio has no adhesive fiber or structures. In comparison of D. rerio and D. rerio var. frankei, the numbers and morphology of appendicular structures on

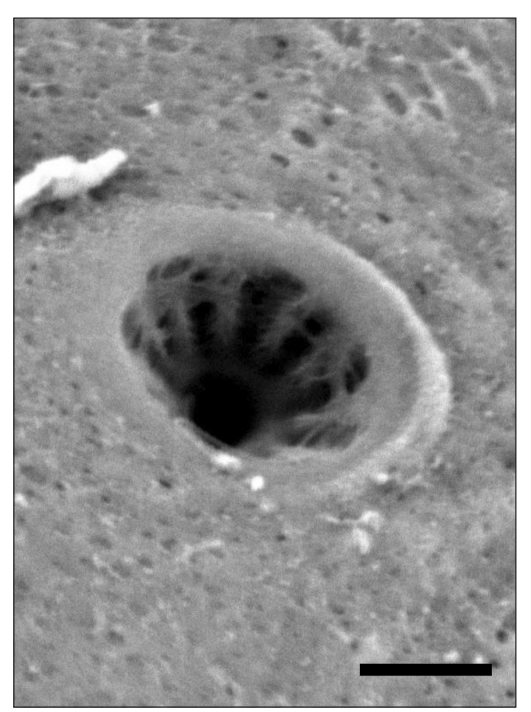

Fig. 3. Micropyle was a funnel shape and it looks like car wheel (scale bar=6 $\mu \mathrm{m})$.

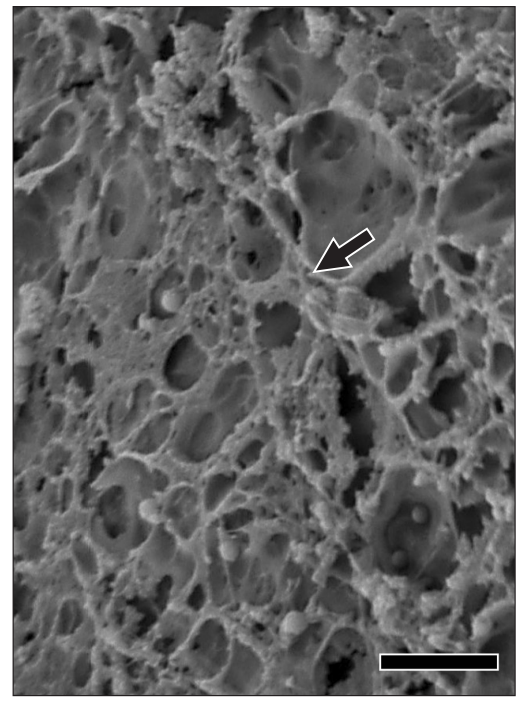

Fig. 4. Scanning electron micrograph of outer surface on the fertilized egg envelope. The adhesive reticular fibers (arrow) were distributed on fertilized egg envelope (scale bar $=10 \mu \mathrm{m})$. 


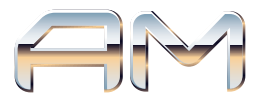

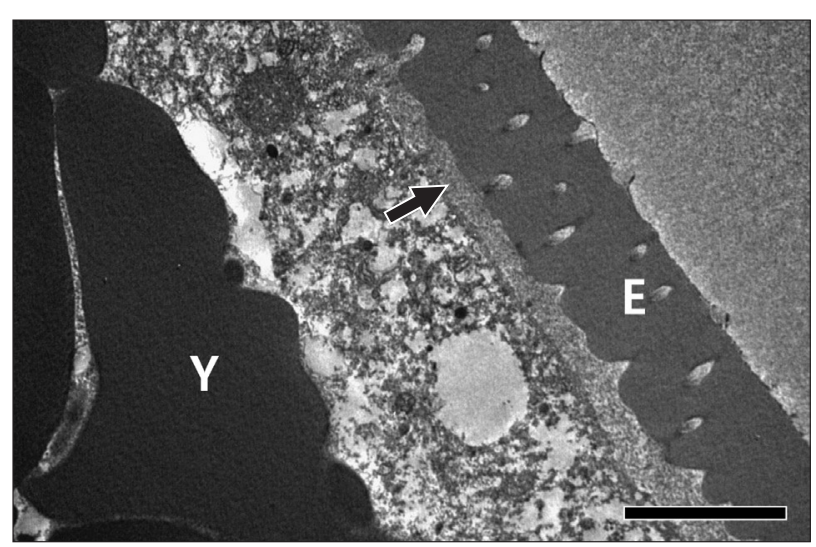

Fig. 5. Cross section of the fertilized egg envelope. Yolks were surrounded by vitelline membrane (scale bar=5 $\mu \mathrm{m}$ ). E, egg envelope; $\mathrm{Y}$, yolk. Arrow: perivitelline space.

the surface of outer layer were different. It was known to be related with the change of body pattern (Joo \& Kim, 2013). Although fishes belong to the same family, the ultrastructure of adhesive fibers was different in each species. In the case of Nothobranchius genus, adhesive fibers have same morphology each other, but the size is different. The adhesive fibers of $N$. guentheri were bigger than N. patrizii (Kwon et al., 2015). Fertilized eggs of tomato clown anemonefish (Eleotrididae) and dark sleepers (Pomacentridae) were non-adhesive type in itself, but the fertilized egg have a bundle of adhesive fibers at the animal pole area (Kim et al., 1998).

\section{Fertilized Egg Envelope Sections}

Under TEM, fertilized egg was surrounded by egg envelope. Lipid droplets and yolks were surrounded by vitelline membrane (Fig. 5). The thickness of egg envelope was about $3.7 \sim 4.2 \mu \mathrm{m}$, and the egg envelope consisted of two layers: an outer, electron-dense adhesive fibers layer and an simple inner layer with pore (Fig. 6). Main content of fertilized egg envelope is glycoprotein and the protein contents of fertilized egg envelope is different in species such as Salmo gairdneri, Gadus morhua, Oncorhynchus mykiss, and Dicentrarchus labrax (Brivio et al., 1991; Cotelli et al., 1988; Oppen-Berntsen et al., 1990; Scapigliati et al., 1994). Therefore these structural proteins can be used to classification of fish as key.

Fertilized egg envelopes of head and tail light fish, black tetra and Buenos aires tetra belong to Characidae consisted of two or three layers, but the number of inner layer is three in head and tail light fish, that of black tetra was four, and that

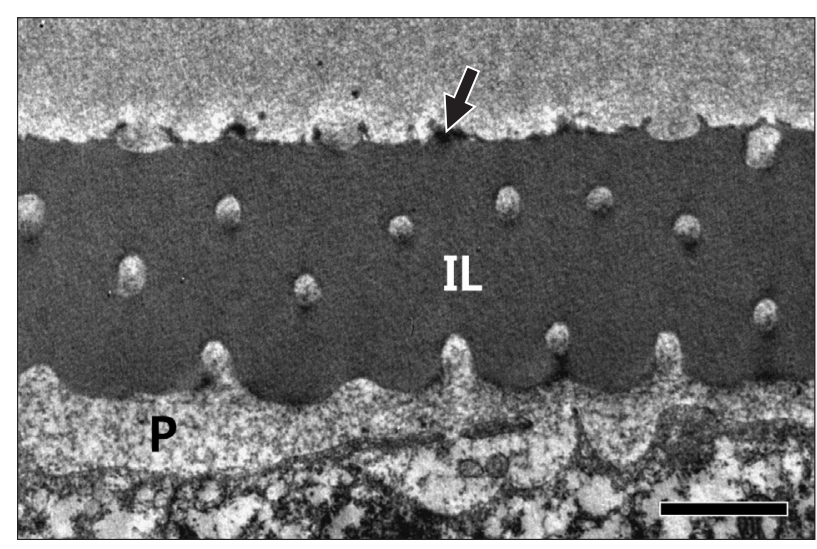

Fig. 6. A transmission electron micrograph of fertilized egg envelope. The egg envelope consisted of two layers: an outer, electron-dense adhesive fibers layer (arrow) and a simple inner layer with pore (scale bar=2 $\mu \mathrm{m}$ ). $\mathrm{IL}$, inner layer; $\mathrm{P}$, perivitelline space.

of Buenos aires tetra was five layers (Kim et al., 1996). In Cichlidae, fertilized egg envelopes of golden severum, convic cichlid, discus, and Cichlasoma managuensis consisted of two layers, but inner layers were differed in species (Deung et al., 1997). And fertilized egg envelopes of Cyprinidae have completely different structure but, it seems to be similar tendency in closer to taxonomical position (Deung et al., 2000; Kim et al., 1998). However, the fertilized egg envelopes of Belontiidae have same morphology (Kim et al., 1999). Therefore, the ultrastructure of the fertilized egg envelope section showed species specificity, but studies on the other species belongs to Bagridae were need to get correct information about common traits in family.

\section{CONCLUSIONS}

We examined the fertilized egg morphology and ultrastructures of surface structures and the cross section of fertilized egg envelopes of $P$. fulvidraco using a light and electron microscopes. The morphology of fertilized eggs and these ultrastructural characteristics of adhesive fibers, outer surface and section of fertilized egg envelope show species specificity, these characteristics can be utilized for classification of species.

\section{CONFLICT OF INTEREST}

No potential conflict of interest relevant to this article was reported. 


\section{REFERENCES}

Anderson E (1974) Comparative aspects of the ultrastructure of the female gamete. Int. Rev. Cytol. Suppl. 4, 1-70.

Bell G R, Hoskins G E, and Bagshaw J W (1969) On the structure and enzymatic degradation of the external membrane of the salmon egg. Can. J. Zool. 47, 145-148.

Brivio M F, Bassi R, and Cotelli F (1991) Identification and characterization of the major components of the Oncorhynchus mykiss egg chorion. Mol. Reprod. Dev. 28, 85-93.

Brummett A R and Dumont J N (1981) A comparison of chorions from eggs of northern and southern populations of Fundulus heteroclitus. Copeia 3, 607-614.

Cameron I L and Hunter K E (1984) Regulation of the permeability of the medaka fish embryo chorion by exogeneous sodium and calcium ions. J. Exp. Zool. 231, 447-454.

Cotelli F, Andronico F, Brivio M, and Lamia C L (1988) Structure and composition of the fish chorion. J. Ultrastruct. Mol. Struct. Res. 99, 70-78.

Deung Y K, Kim D H, and Reu D S (2000) Ultrastructure of the fertilized egg envelope from pale chub, Cyprinidae, teleost. Korean J. Electron Microsc. 30, 321-326.

Deung Y K, Reu D S, and Kim D H (1997) Comparative ultrastructures of the fertilized egg envelopes in golden severum, convic cichlid and discus, Cichlidae, teleost. Korean J. Electron Microsc. 27, 417-432.

Donovan M J and Hart N H (1986) Cortical granule exocytosis is coupled with membrane retrieval in the egg of Brachydanio. J. Exp. Zool. 237, 391-405.

Grierson J P and Neville A C (1981) Helicoidal architecture of fish eggshell. Tissue Cell 13, 819-830.

Hamazaki T S, Nagahama Y, Luchi I, and Yamagami K (1989) A glycoprotein from the liver constitutes the inner layer of the egg envelope (zona pellucida interna) of the fish, Oryzias latipes. Dev. Biol. 133, 101-110.

Harvey B, Kelley R N, and Ashwood-Smith M J (1983) Permeability of intact and dechorionated zebrafish embryo to glycerol and dimethyl sulfoxide. Cryobiology 20, 432-439.

Huh M K, Choi J S, Heo Y S, and Lee B K (2007) Genetic diversity and population structure of Pseudobagrus fulvidraco in the Nakdong river. J. Life Sci. 17, 882-888.

Joo K B and Kim D H (2013) Comparative ultrastructures of the fertilized egg envelopes in Danio rerio and Danio rerio var. frankei, Cyprinidae, Teleostei. Appl. Microsc. 43, 14-20.

Kim D H, Deung Y K, Kim W J, Reu D S, and Kang S J (1999) Comparative ultrastructures of the fertilized egg envelopes from three-spot gourami, pearl gourami and marble gourami, Belontiidae, teleost. Korean J. Microsc. 29, 343-351.

Kim D H, Reu D S, and Deung Y K (1996) A comparative study on the ultrastructures of the egg envelope in fertilized eggs of fishes, Characidae, three species. Korean J. Microsc. 26, 277-291.

Kim D H, Reu D S, and Deung Y K (1998) Comparative ultrastructures of the fertilized egg envelopes in three species, Cyprinidae, teleost. Korean J. Microsc. 28, 237-253.

Kim I S and Park J Y (2002) Freshwater Fishes of Korea, pp. 235-236, (Kyo-Hak Publishing Co., Ltd., Seoul).

Kwon J K, Jung H S, and Kim D H (2015) Comparative ultrastructures of the fertilized egg envelopes in Nothobranchius guentheri and Nothobranchius patrizii, Nothobranchiidae, Teleostei. Appl. Microsc. 45, 144-149.

Laale H W (1980) The perivitelline space and egg envelopes of bony fishes: a review. Copeia 2, 210-226.

Lee Y H (1998) Ultrastructure of spermatozoa in the bagrid catfish, Pseudobagrus fulvidraco (Teleostei, Siluriformes, Bagridae). Korean J. Electron Microsc. 28, 39-48.

Lim S G and Han C H (1997) Annual reproductive cycle of the banded catfish, Pseudobagrus fulvidraco (Richardson). J. Korean Fish. Soc. 30, 823-833.

Lim S G and Han C H (2012) Effect of water temperatures and photoperiods on gonadal development in banded catfish Pseudobagrus fulvidraco. J. Fish. Mar Sci. Edu. 24, 854-861.

Ohta T and Nashirozawa C (1996) Sperm penetration and transformation of sperm entry site in eggs of the freshwater teleost Rhodus ocellatus ocellatus. J. Morphol. 229, 191-200.

Oppen-Berntsen D O, Helvik J V, and Walther B T (1990) The majo structural proteins of cod (Gadus morhua) eggshells and protein crosslinking during teleost egg hardening. Dev. Biol. 137, 258-265.

Scapigliati G, Carcupino M, Taddei A R, and Mazzini M (1994) Characterization of the main egg envelope proteins of the sea bass Dicentrarchus labrax L. Mol. Reprod. Dev. 38, 48-53.

Schmehl M K and Graham E F (1987) Comparative ultrastructure of the zona radiata from eggs of six species of salmonids. Cell Tissue Res. 250, 513-519.

Stehr C M and Hawkes J W (1979) The comparative ultrastructure of the egg membrane and associated pore structures in the starry flounder, Platichthys stellatus (Pallas), and pink salmon, Oncorhynchus gorbuscha (Walbaum). Cell Tissue Res. 202, 347-356. 